\title{
OPTIMIZATION METHODOLOGY FOR HIGH COD NUTRIENT-LIMITED WASTEWATERS TREATMENT USING BAS PROCESS
}

\author{
Marta Revilla ${ }^{\mathrm{a}}$, Berta Galán ${ }^{\mathrm{b}}$, Javier R. Viguri ${ }^{\mathrm{b} *}$ \\ a SNIACE, Carretera de Ganzo S/N 39300 Torrelavega Cantabria, Spain. \\ ${ }^{b}$ Green Engineering \& Resources Research Group (GER). Department of Chemical and \\ Process \& Resources Engineering. ETSIIT. University of Cantabria. Avenida los Castros \\ s/n. 39005, Santander, Cantabria, Spain. \\ *Corresponding author: Tlf: 30-942-201589; Fax: 30-942-206706,vigurij@unican.es \\ Javier R. Viguri: ORDIC Code:0000-0002-6658-0429 \\ Berta Galan: ORCID Code: 0000-0003-2145-3669 \\ Keywords: biofilm activated sludge, methodology, optimization, operational costs, \\ effluent quality, decision making.
}

\begin{abstract}
Optimization of biofilm activated sludge (BAS) process via mathematical modelling is an entangle activity since economic, environmental objective and technical decision must be considered. This paper presents a methodology to optimize the operational conditions of BAS process in four steps by combining dynamic simulation techniques with nonlinear optimization methods and with operative decision making criteria. Two set of variables are separately prioritized in the methodology: essential variables related to physical operation to enforce established process performance, and refinement variables related to biological processes that can generate risks of bulking, pin-point floc and rising sludge. The proposed optimization strategy is applied for the treatment of high COD wastewater under nutrient limitation using an integrated mathematical model for COD removal that include predation, hydrolysis and a simplified approach to the limiting solids
\end{abstract}


flux theory in the secondary clarifier in order to facilitate the convergence of the optimization solver. The methodology is implemented in a full scale wastewater treatment plant for a cellulose and viscose fibre mill obtaining: i) improvement of the effluent quality index ( $\mathrm{Kg}$ pollution $/ \mathrm{m}^{3}$ ) up to $62 \%$ and, ii) decrease the operating cost index $\left(€ / \mathrm{m}^{3}\right)$ of the process up to $30 \%$ respect the regular working operational conditions of the plant. The proposed procedure can be also applied to other biological treatments treating high COD nutrient-limited industrial wastewater such as from textile and winery production among others.

\section{Introduction}

Emission limits for industrial effluent are constantly being tightened up. Activated sludge (AS) process is a common system for biological treatment of industry effluents; however, more sustainable solutions require other technologies such as biofilm activated sludge process (BAS). BAS is composed of moving bed biofilm reactor (MBBR) and activated sludge reactor (AS) that are used as bacterial and predator stage respectively (Sointio et al. 2006, Revilla et al. 2016a). The overall result in BAS processes increases COD removal performance respect to other conventional treatment and, at the same time, lay out lower sludge production. An additional and determining benefit is the improvement sludge settleability in the final stage of secondary settling (Rankin et al. 2007) that allows that the activated sludge reactor to be operated at increased biomass concentration while simultaneously total suspended solids (TSS) concentration in the effluent can be reduced (van Haandel and van der Lubbe 2015). Moreover, this biologic double stage process can avoid the risk of bulking when it is operated under nutrients limitation (Rankin et al. 2007). Predation is the powerful mechanism of the BAS process that allows achieving their main characteristic as the low sludge yield. 
Modelling of biofilm stages and activated sludge provided a better understanding of the intrinsic connections between soluble and particulate compounds, biomass properties and process performance in terms of COD, BOD and TSS (Fan et al. 2017). Commercial simulation platforms, including GPS-X and BioWin can be used to describe the one dimensional (1-D) multi-species biofilm structure and biological behaviour of the treatment process ( $\mathrm{Li}$ et al. 2016); however, none of these platforms include the description of the predator microorganism which plays a predominant role in a BAS process under certain conditions such as nutrient limited conditions (Revilla et al. 2016a).

The authors published recently the mathematical model of BAS process including hydrolysis and predation and uses wastewaters coming from viscose and cellulose production industrial process to validate the model. In Revilla et al. 2016a the whole BAS process was simulated and the evaluation of the role and contribution of predator microorganisms towards COD removal, nutrient requirements and sludge production is displayed.

More strict regulations are being imposed regularly in terms of COD, BOD and TSS removal that enforce wastewater treatment technologies to progress (Guerrero et al. 2011; Kamali and Khodaparast 2015). Optimization of an existing facility in terms of cost, operational improvements and removal efficiency is the most effective method of achieving the stricter compliance and the most effective method to overtake common trade-off between treatment results and operational costs. However, expectation of having to satisfy simultaneously a variety of objectives (environmental, economic and technical) increases the complexity of the problem and becomes a very difficult task that should be solved blending experience engineers and specific mathematical tools (Descoins et al. 2012; Hakanen et al. 2013). In this context, practical experience of the operator in the prioritization of conflicting objectives or in the application of rules of thumb, needs to be 
considered in the mathematical model since certain units at wastewater treatment plant

80 (WWTP) may be exceptionally difficult or risky to operate.

81 Multiple objective optimization (MOO) has been widely applied in operation and design

82 of municipal WWTP for different applications using interactive approaches between

83 several optimization and decision making tools (Dai et al. 2016; Garrido-Baserba et al.

84 2016; Hakanen at al. 2011; Rivas et al. 2008; Sweetapple et al. 2014). However, a

85 systematic methodology of multiple objective optimization of a full-scale BAS process

86 has not been addressed, to the best of our knowledge.

87 Generally, urban wastewater has high presence of nutrients that facilities the biological

88 process; however, some type of wastewater such as viscose and cellulose industry

89 wastewater are poor in nutrients that must be added externally with the consequent

90 increase in the operating costs of biological treatments (Rankin et al. 2007).

91 In this paper, an optimization methodology for BAS processes treating highly COD

92 wastewater under limited nutrient is presented. Simultaneous optimization of effluent

93 quality and operating cost under prioritized technical specifications is the main goal of

94 this procedure. Applicability of the proposed methodology for biological treatment

95 processes using biofilm is illustrated using two industrial-scale case studies from viscose

96 and cellulose wastewaters.

97

98

99

100 


\section{Identification of the problem}

102

103

104

105

106

107

108

109

110

111

112

113

114

115

116

117

118

119

120

121

122

123

124

125

\subsection{Problem statement}

The problem of optimizing the operational conditions of the BAS plant can be stated as follows: given is a BAS plant with known design parameters and given is an influent stream with known flow rate that contain certain pollutants with known concentrations; the goal of this problem is to identify the operational conditions of the plant at minimal operational cost and minimal pollutant discharge in the effluent stream taking into account technical specifications.

To solve this problem a conceptual optimization methodology approach, based on four sequential stages showed in Figure 1, is proposed in this work. As explained previously, BAS process included two biological sequential steps: MBBR reactor and AS reactor. In MBBR reactor nutrient dosing is the unique variable that can be manipulated. Furthermore, the mathematical model of the MBBR reactor presented previously by the authors (Revilla et al. 2016b) is a multi-substrate biofilm and bulk liquid model and the mathematical model of the AS is continuous stirred-tank reactor. These two biological sequential steps described (MBBR and AS) are the base of the four sequential stages of the optimization methodology.

Starting from the regular operation conditions of an industrial plant, the first stage of the optimization methodology is the "Synthesis of Alternatives"; nutrient different dosage is the essential variable of the process (performance and cost) being used to generate different process alternatives. All the alternatives are simulated for MBBR reactor in the second stage "Simulation” using a previous MBBR mathematical method; besides, the results of "Simulation" allows obtaining the initial point of the variables of the AS process. The third step is the “Activated Sludge Multicriteria Optimization” that allows to obtain optimal solutions of the process variables under economic and environmental 
evaluation criteria. This procedure ("Simulation of MBBR" and later "Activated Sludge Multicriteria Optimization”) requires much less computation computational effort than using an optimization software under dynamic and spatial conditions.

The last stage is the "Decision Making Process" where a set of refinement operation bound let to obtain the optimal conditions under additional evaluation criterion. The proposed methodology is iterative until the optimal solution is reached.

(1)

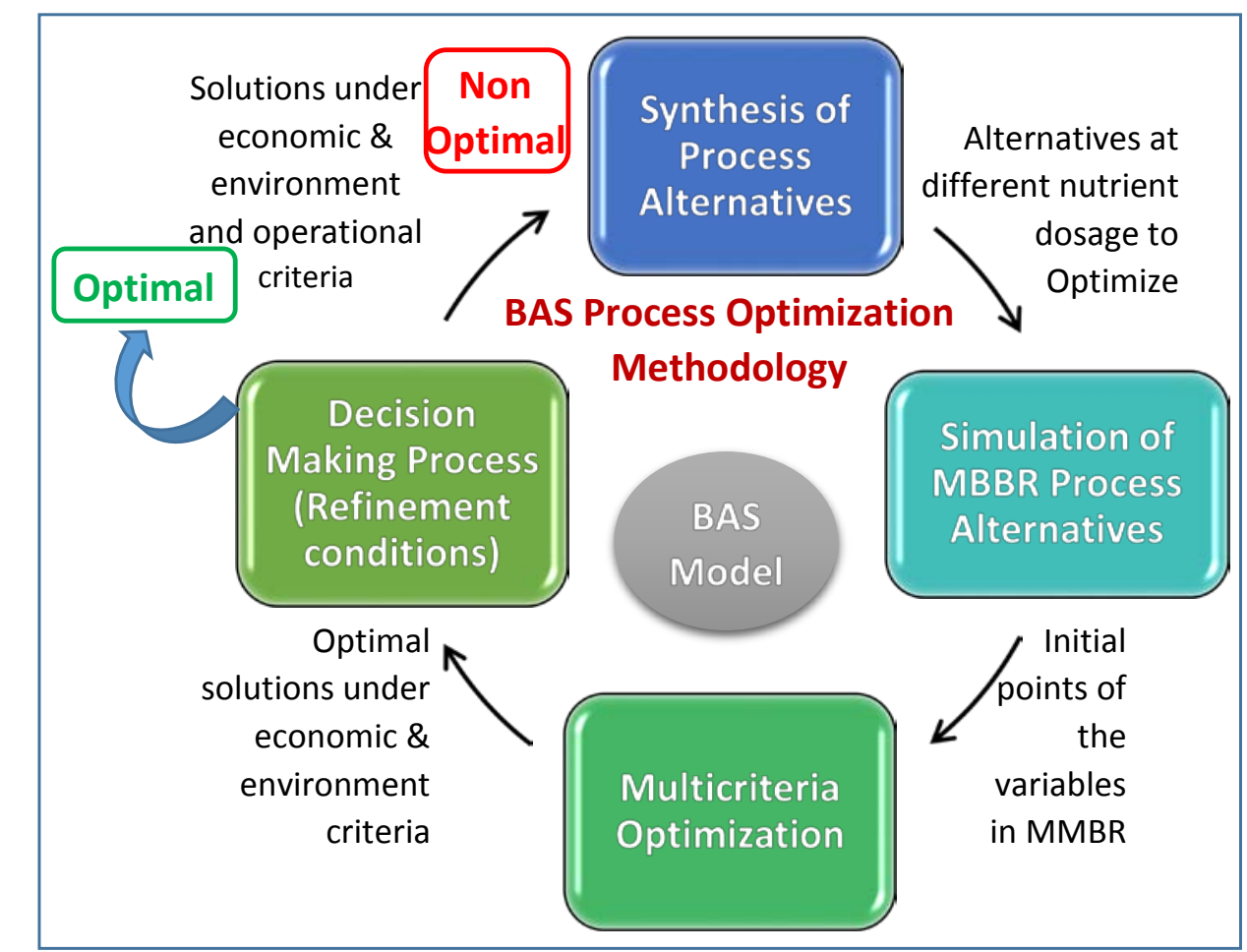

Figure 1.- Conceptual optimization methodology approach.

\subsection{BAS mathematical model}

A complete description for the mathematical models of four units involved in the BAS process (MBBR, AS, secondary clarifiers and splitter) including the biological reactions, stoichiometric and kinetic coefficients appears in previous papers presented by the authors (Revilla et al. 2016a, b). In the present paper a significant modification has been done in the mathematical model of secondary clarifier in order to evaluate the clarification and thickening functions; a "simplified approach" proposed by von Sperling (2007) to the 
151 limiting solids flux theory has been included in the model. Limiting solids flux concept

152 is widely used in the bibliography trough the "non-differentiable minimum function" 153 (Amanatidou et al. 2015a, b) which requires iterative methods to solve it numerically and 154 can raise convergence issues when uses optimization algorithms (Hreiz et al. 2015a). The 155 use of the simplified approach facilitates the convergence of the optimization algorithms.

156 The simplified approach proposed by von Sperling (2007) takes into account four 157 variables i) hydraulic loading rate (HLR) which corresponds to the quotient between the 158 influent flow rate $\left(\mathrm{Q}_{\mathrm{i}}\right)$ and the surface area of the secondary settler $(\mathrm{A})$ (equation 1$)$, ii) 159 solids loading rate (SLR) which corresponds to the quotient between applied solids load 160 and the surface area of the secondary settler (equation 2), iii) sludge settling velocity (v) (equation 3) and, iv) limiting solids flux (GL) (equation 4):

162

163

164

165

166

$\operatorname{HLR}\left(\mathrm{m}^{3} / \mathrm{m}^{2}\right.$ hour $)=Q_{\mathrm{i}} / \mathrm{A}$

$\operatorname{SLR}\left(\operatorname{Kg} \mathrm{TSS} / \mathrm{m}^{2}\right.$ hour $)=\left(\mathrm{Q}_{\mathrm{i}}+\mathrm{Q}_{\mathrm{R}}\right) \times \mathrm{TSS}_{\mathrm{AS}} / \mathrm{A}$

$\mathrm{v}\left(\mathrm{m}^{3} / \mathrm{m}^{2}\right.$ hour $)=(\mathrm{vo}) \times \mathrm{e}^{-\mathrm{K} \times \mathrm{TSS}_{\mathrm{AS}}}$

GL $\left(\right.$ Kg TSS $/ \mathrm{m}^{2}$ hour $)=m\left(Q_{R} / A\right)^{n}$

where $\mathrm{QR}_{\mathrm{R}}$ is the sludge recycle flow rate; $\mathrm{TSS}_{\mathrm{AS}}$ are the total suspended solid concentrations in AS reactor; vo, $\mathrm{K}, \mathrm{m}$ and $\mathrm{n}$ are specific correlation parameters.

In this work, “fair settleability”, with sludge volume index (SVI) between 100-200 mL/g, vo (8.6 m/hour), $\mathrm{K}\left(0.50 \mathrm{~m}^{3} / \mathrm{Kg}\right)$, $\mathrm{m}(0.72)$ and $\mathrm{n}(8.41)$ is considered.

Finally, two new conditions are included in the previous BAS mathematical model developed by the authors in order to ensure the clarification and thickening function.

- Clarification function: hydraulic loading rate (HLR)<sludge settling velocity (v)

- Thickening function: solid loading rates (SLR)<limiting solid flux (GL) 
174 Blue section of the Figure 2 shows the essential attributes of the BAS process model 175 including the appropriated operational variables and its constraints and bounds for the 176 secondary settler tank and for the AS reactor apply in the present work. These suitable

177 operational variables are included due to operational consistencies (Espírito Santo et al. 178 2013) even though other authors can point out lightly different values (Henze 2008; Hreiz 179 et al. 2015a; van Haandel and van der Lubbe 2015).

\section{Optimization methodology}

181 The complexity for simultaneous reduction of operational costs, reduction of the amount of pollutants discharged into sewer together with reduction of sludge generated, and the requirement of a technically well-operated full-scale wastewater plant have motivated this paper. Furthermore, this optimization process involves some other challenges such as, i) high number of (non-linear) equations and variables, and ii) dynamic and spatial distribution of the components into the length of the biofilm of the MBBR rectors.

The optimization methodology to fulfil the proposed objectives is divided into four consecutive steps detailed in the following sections. This approach simplifies the convergence of the mathematical models and the determination of the initial points of the variables. A detailed flowchart of the proposed optimization methodology and the relation with the mathematical model is shown in Figure 2.

This methodology can be used for wastewater under nutrient limitations coming from different industrial sector such as pulp and paper, petrochemical, pharmaceutical or food 


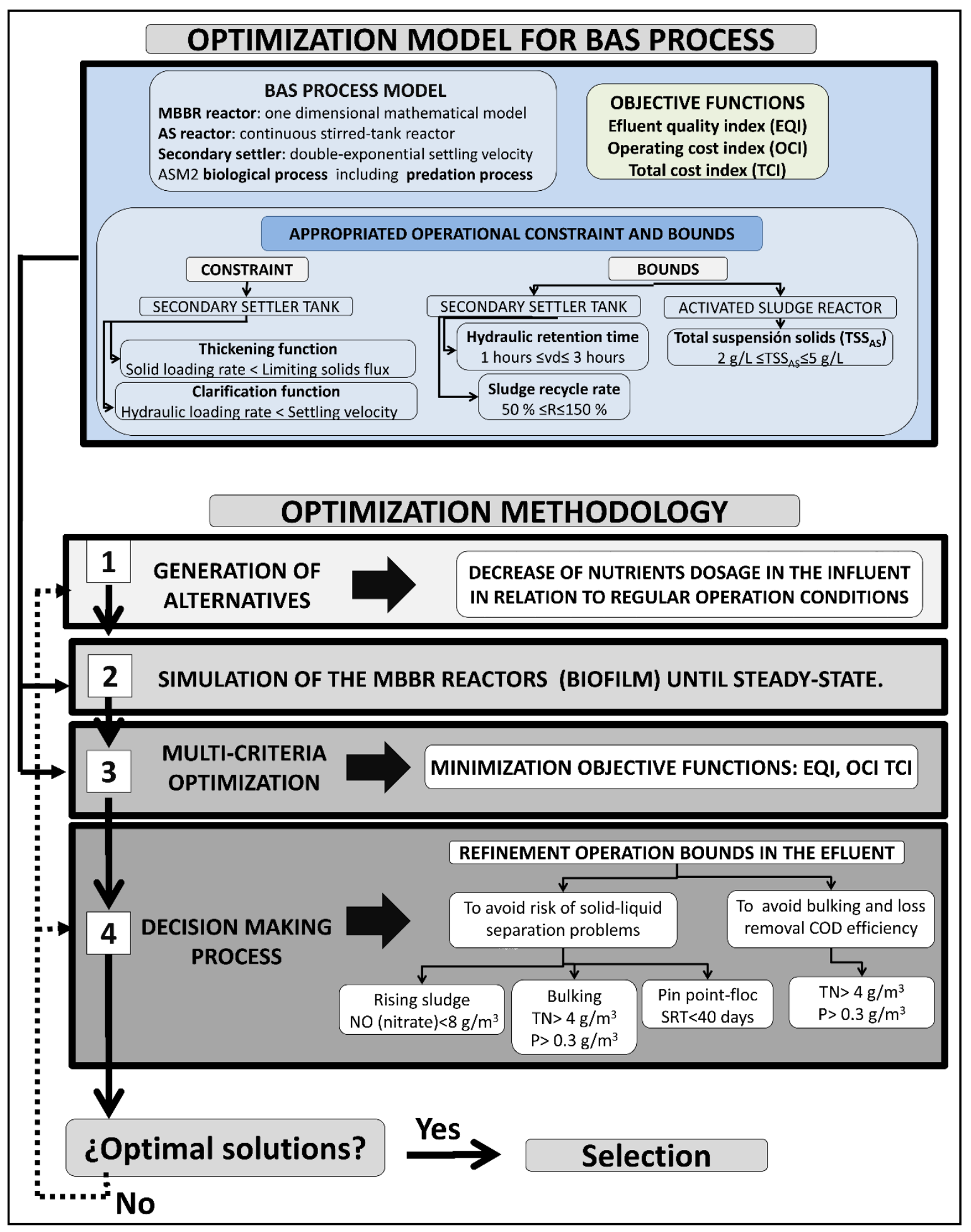

Figure 2. Flowchart of the optimization methodology.

\subsection{Generation of alternatives}

198 Nutrients must be dosed into the influent to ensure the proper growth of the 199 microorganisms because the BAS process under-study treats high COD wastewater under 
limited nutrient condition. The optimization methodology starts generating alternatives

201

202

203

204

205

206

207

208

by selecting one independent variable as additional constraint (Hreiz et al. 2015b). The selected variable in this work is the nutrient dosage in the influent; this variable affects the behaviour of MBBR reactors and the overall performance and cost of the BAS process. Different intervals of the nutrient dosage are considered to generate several alternatives depending on the precision degree required for the optimization process.

\subsection{Simulation of the MBBR reactors (biofilm) until steady-state.}

The mathematical model of the MBBR reactor previously developed by the authors (Revilla et al. 2016b) allows the determination of the concentration of the components in the reactor with time and the spatial distribution along the length of the biofilm. The AS model used by the authors for the AS step is simpler than MBBR model since it is modeled as a continuous stirred-tank (Revilla et al, 2016a).

The optimization methodology separates the BAS process into two stages: simulation of the MBBR reactor and optimization of the rest of BAS process. The simulation stage fulfils two aspects: i) solve a complex multi-species and multi-substrate biofilm and bulk liquid MBBR model and ii) facilitates the determination of the initial points of the variables for optimization process.

In the previous as well as in the present work, general chemical engineering process software (Aspen Custom Modeler) is used to simulate the behaviour of MBBR reactors since this software facilitates the creation of rigorous dynamic and spatial model. In this second stage of the optimization, this MBBR model is used to simulate the behaviour of the components for each alternative in the biofilm and in the reactor until steady-state. Once the steady-state is reached, the MBBR results of each alternative are sent to third stage of the methodology: optimization of the conditions of the BAS process. 


\subsection{Multicriteria optimization}

Once MBBR behaviour is simulated until steady-state, the rest of the process is optimized for each alternative using three different index as objective functions: total cost index, effluent quality index or/and operating cost index as objective functions. The optimization of the BAS process is done by the software General Algebraic Modeling System (GAMS) using CONOPT as NLP algorithm (El Shorbagy et al. 2013).

\subsubsection{Objective functions}

Three indexes are used as objective functions to be minimized in the present work: effluent quality index (EQI) that measure the presence of pollutant in the effluent, and operating cost index (OCI), that evaluates operation expenses in the plant. An additional index, the total cost index (TCI) linking effluent quality and operating cost indexes, is considered as objective function by weighting method (Flores-Alsina et al. 2008).

\section{Effluent quality index (EQI)}

The effluent quality index (EQI) (Copp 2002; Foscoliano et al. 2016) quantifies into a single term, the effluent pollution load into a receiving water body (kg pollution/day) (Vanrolleghem and Gillot 2002). The discharged of different pollutants into the effluent is considered as a weighted sum of six evaluation criteria: total Kjeldahl nitrogen (TKN), COD, BOD, TSS, nitrate (NO) and total phosphorous (P). Equation 5 shows the weighted sum of each evaluation criteria where $Q_{e}$ is the effluent flow rate.

$\mathrm{EQI}\left(\mathrm{Kg} \frac{\text { pollution }}{\text { day }}\right)=\left[20 \times \mathrm{TKN}\left(\frac{\mathrm{g}}{\mathrm{m}^{3}}\right)+1 \times \operatorname{COD}\left(\frac{\mathrm{g}}{\mathrm{m}^{3}}\right)+2 \times \mathrm{BOD}\left(\frac{\mathrm{g}}{\mathrm{m}^{3}}\right)+2 \times\right.$

$\left.\operatorname{TSS}\left(\frac{\mathrm{g}}{\mathrm{m}^{3}}\right)+20 \times \mathrm{NO}\left(\frac{\mathrm{g}}{\mathrm{m}^{3}}\right)+100 \times \mathrm{P}\left(\frac{\mathrm{g}}{\mathrm{m}^{3}}\right)\right] \times \mathrm{Q}_{\mathrm{e}}\left(\frac{\mathrm{m}^{3}}{\mathrm{day}}\right) \times 10^{-3}$ 
247 The operating cost index (OCI) that is used as the economic objective function, is an

248 approximate measure of the plant's operational cost, involves the main operating costs,

249 such as power consumption by aerators, sludge production, pumping energy and nutrient

250 cost. The operating cost index (OCI) (equation 6) is calculated as the weighted sum of

251 aeration energy associated to the oxygen consumption for the carbonaceous demand

252 (CD), aeration energy associated to the oxygen consumption for the nitrogenous demand

253 (ND), mixing energy (ME), pumping energy (PE), sludge production (SP) and nutrient

254 cost (NC), using the weighting factors as Chen et al. 2015 and Zhou et al. 2015.

255 OCI $(€ /$ year $)=25 \times(\mathrm{CD}+\mathrm{ND}+\mathrm{ME}+\mathrm{PE})+75 \times \mathrm{SP}+\mathrm{NC}$

Total cost index (TCI)

257 Total cost index (TCI) is defined in equation 7 as the sum of the effluent quality index and operating cost index optimized (Vanrolleghem and Gillot 2002; Kim et al. 2015).

TCI $(€ /$ year $)=50 \times$ EQI $($ Kg pollution/day $)+$ OCI $(€ /$ year $)$

Along the paper the values of EQI, OCI and TCI were calculated per $\mathrm{m}^{3}$ of wastewater treated (Guerrero et al. 2011) in order to maintain the confidentiality of the industrial effluent characterization.

\subsection{Decision making process}

264 The proposed optimization strategy produces one optimal solution for each alternative 265 and for each selected objective function. The variables included in the step 1 are related to operational conditions that are essential to obtain a minimum AS performance process.

267 The last part of the methodology considers refinement conditions by including some 
variables related to the biological processes to avoid risks of inefficiencies in the downstream liquid-solid separation processes; these variables can be used as decision making process. Even though most of the optimization models do not include priority levels such as essential operational variables and refinement operation variables, the incorporation of this type of prioritization allows extending the use of the methodology under circumstances where refinement variables or bounds can be skipped. The AS and clarifying units of the BAS process can run even without fulfilling the bounds of some of these refinement conditions but, generally, fulfilling them improve the behaviour of the BAS process.

The last unit of the BAS process is the separation of sludge from wastewater in the secondary settler since most of the sludge is returned to AS tank while a minor part is taken out to be wasted. The separation of the sludge depends on the microorganism growing in large aggregate called flocs; however, the microorganisms do not always grow in the adequate form leading to sludge separation problems.

Avoiding the risk of separation solid-liquid problems in the secondary settler and loss of COD removal efficiency in the overall BAS process were selected as refinement o decision making requirements (Comas et al. 2008; Flores-Alsina et al. 2009). In the present work, these aspects have been tackled by considering some variables in the unit models and by adapting the upper or lower limits of these variables to the wastewater and process under study, as pointed out in the fourth step of Figure 2.

If after the decision making process none optimal conditions have been obtained it is necessary to come back to step 1 (generation of alternatives) to extend the number of alternatives or to come back to step 4 to extend the bounds of the decision-making variables. 


\section{Industrial installation}

293 Veolia have installed more than 90 BAS plants worldwide to treat wastewater from pulp 294 industry. In this work, the full-scale BAS process for biological COD removal consist of: 295 an equalization tank $\left(1,600 \mathrm{~m}^{3}\right)$, two MBBR reactors in-series $\left(5,331 \mathrm{~m}^{3}\right)$, an AS reactor $296\left(47,000 \mathrm{~m}^{3}\right)$, two parallel secondary settler tanks (volume 4,143 $\mathrm{m}^{3}$ and 1,017 $\mathrm{m}^{2}$ unit 297 surface area) and one splitter to recirculate part of the sludge and to disposal the remaining 298 part (Figure 3). The equalization tank is also used to dose nitrogen as urea (40\% w/w) and 299 phosphorous as phosphoric acid (72\%). The MBBR reactors were filled with carriers type 300 BiofilmChip P of Veolia's AnoxKaldnes ${ }^{\mathrm{TM}}$ to $10 \%$ of volume. The aeration system in 301 MBBR reactors uses a blower of a unit air flow 31,600 $\mathrm{Nm}^{3} / \mathrm{h}$ for each MBBR reactor and perforated tubes in the bottom of reactor to produce medium bubbles ( $3 \mathrm{~mm}$ of diameter) with a high mixing capacity and medium oxygen transfer efficiency (16 \%). The aeration system of AS reactor uses one blowers of a unit air flow 31,600 Nm³/h and diffusers of membrane to produce fine bubbles (1 $\mathrm{mm}$ of diameter) with a high mixing capacity and high oxygen transfer efficiency (45.5\%). Due to the high oxygen transfer efficiency in the AS reactor, the airflow supplied by the blower associated to the oxygen consumption for the carbonaceous (CD) and nitrogenous demand (ND) is lower than in the MBBR reactors resulting in a lower energy consumption (von Sperling 2007). 


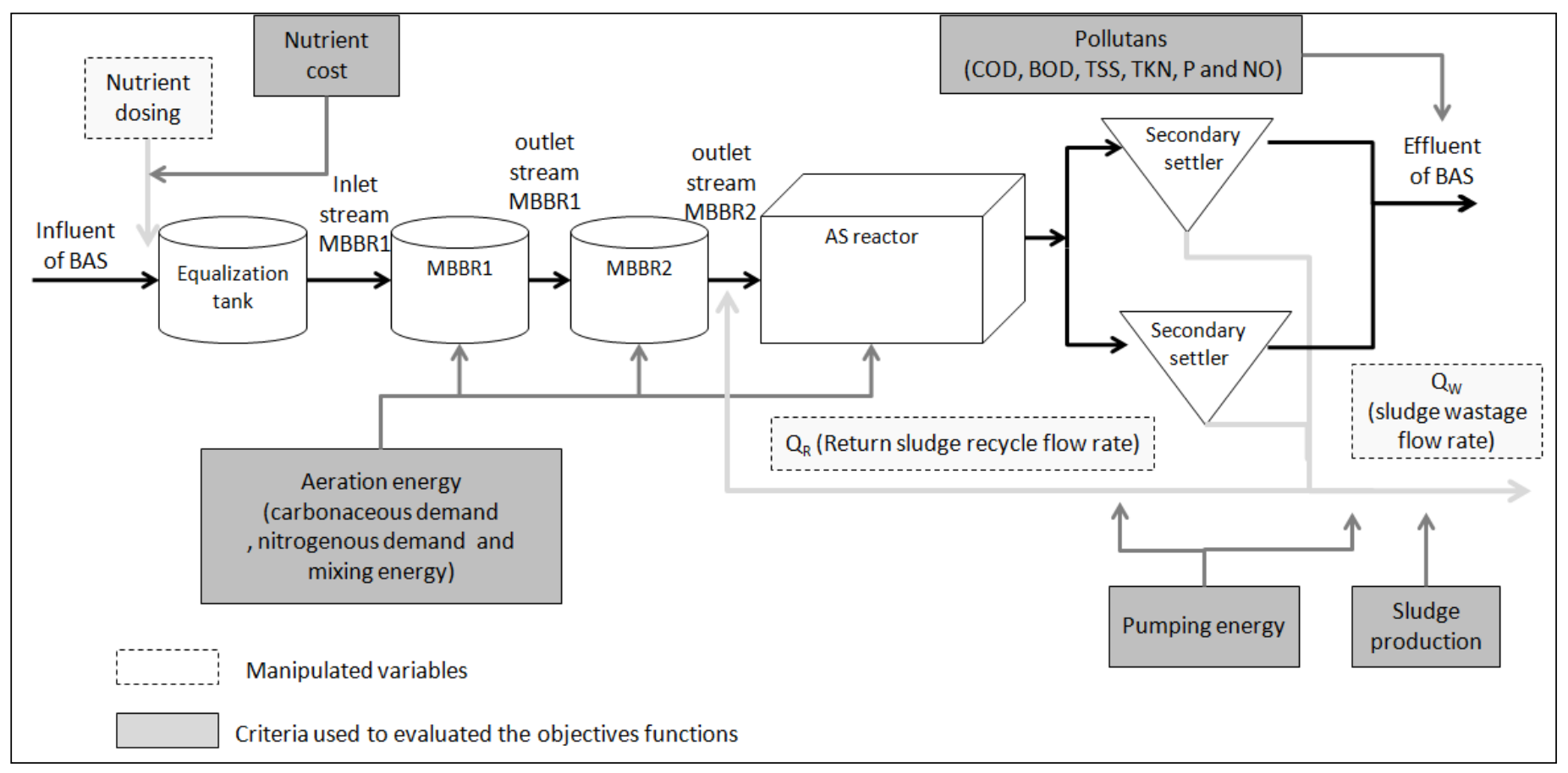

311 Figure 3. Flow sheet of the full-scale BAS process with detail of the manipulated variables

312 and criteria used to evaluate the objective functions.

314 The full-scale real BAS plant works under two different conditions (case-study A and B)

315 due to different industrial production requirements of the pulp integrated plant. The case-

316 study A treats wastewater from viscose and cellulose industry and the case-study B treats

317 wastewater from cellulose industry. The regular operational conditions of the studied

318 industrial BAS process (Table 1) are based on the industrial heuristic knowledge.

319 The low values of nutrient dosage used in this work in comparison with the "thumb rule"

320 (100 COD:5 N:1 P) are explained by the large amounts of nutrients that are regenerated

321 in the AS reactor (Comeau et al. 2003) since the biomass is consumed by predator

322 microorganisms.

323 Table 1 additionally lists a summary of the main outlet stream characteristics obtained

324 working at these regular operational conditions that reach a high COD removal 

the objective indexes obtained working at regular operational conditions appear at the end of Table 1.

Table 1.Characteristics of regular working conditions for the two case-studies of the BAS process together with the variables and indexes obtained for these conditions.

\begin{tabular}{|l|l|c|c|}
\hline \multicolumn{2}{|c|}{ Parameters of the treatment plant at regular operation } & Case-study A & Case-study B \\
\hline $\begin{array}{l}\text { Influent } \\
\text { conditions }\end{array}$ & Wastewater origin & Viscose \& Cellulose & Cellulose \\
\hline \multirow{3}{*}{ Manipulated } & $\mathrm{Q}_{\mathrm{i}}\left(\mathrm{m}^{3} / \mathrm{day}\right)$ & $1.0 \mathrm{q}^{*}$ & $0.59 \mathrm{q}^{*}$ \\
variables & Vd (hours) & 3.12 & 6.07 \\
& $\mathrm{COD} \mathrm{f}: \mathrm{N}: \mathrm{P}$ & $100: 2.14: 0.28$ & $100: 1.13: 0.24$ \\
& $\mathrm{R}(\%)$ & 110 & 80 \\
& $\mathrm{SRT}(\mathrm{Days})$ & 19 & 30 \\
& $\left.\mathrm{Qw}^{3} / \mathrm{day}\right)$ & 1,082 & 636 \\
\hline Key & COD removal percentage & 76 & 85 \\
variables & Sludge yield (Tn TSS/Tn COD removed) & 0.207 & 0.155 \\
& Efficiency (Tn COD removed/day) & 35.4 & 28.3 \\
\hline Objective & TCI (Total cost index) $\left(€ / \mathrm{m}^{3}\right)$ & 0.431 & 0.401 \\
indexes & QQI (Effluent quality index $\left(\mathrm{Kg}\right.$ pollution $\left./ \mathrm{m}^{3}\right)$ & 1.790 & 0.861 \\
& OCI (Operating cost index) $\left(€ / \mathrm{m}^{3}\right)$ & 0.186 & 0.245 \\
\hline
\end{tabular}

*Reference value: $\mathrm{q}$ for $\mathrm{Q}_{\mathrm{i}}$.

It is important to remark that hydraulic retention time in the secondary settler $(v d)$ for a well-driven BAS plant should be between 1-3 hours (van Haandel and van der Lubbe 2015); however, vd is 6.07 hours in case-study B, therefore, in the present paper for optimization purpose, only one secondary settler tank is considered in the case-study B since the usage of two secondary settlers would give infeasible solutions.

\section{Results and discussion}

\subsection{Generation of alternatives}

Nutrient needs to be dosed in the influent of viscose and cellulose wastewater since this considering that: i) nutrient overdosing can produce effluents with high nitrogen and

342 phosphorus discharges into the sewer (Malmqvist et al. 2007) or unwanted nitrifying 
bacteria, which consume oxygen and generates additional liquid-solid separation problem due to denitrification in secondary settler tanks (Henze 2008), ii) severe deficiency of $\underline{\text { nutrient }}$ results in a loss of COD removal efficiency and bulking (van Haandel and van der Lubbe 2015; Welander et al. 2002) and, iii) nutrient dosage also influences the sludge production and reduction on dosage can result in growth limitation in the MBBR reactors and a consequent reduction of the waste sludge production (Welander et al. 2002).

Nutrient dosage is incorporated in the mathematical model in order to generate a wide number of alternatives. The dosage used in the regular operation condition is considered the starting point for the generation of alternatives (100:2.14:0.28 for case study A and 100:1.13:0.24 for case-study B); and the alternatives are generated by decreasing nitrogen and phosphorous dosage by 5\% until the efficiency of the process (Tn de COD removed by day) decreases more than $2.0 \%$ in relation to the regular operation conditions. In this generated until nutrient dosage value of 100:0.34:0.07. Alternatives generated are enough for this study but higher number of alternatives can be easily considered if necessary when the characteristics of the processes are particularly sensitive.

\subsection{Simulation of the MBBR reactors until steady-state}

The MBBR reactors of the treatment plant under-study are simulated using Aspen Custom Modeler software to describe the dynamic and longitudinal behaviour of the reactors. The generated alternatives with different nutrient dosage are simulated during 30 days until steady-state is reached. Once steady-state is attained, the simulated results obtained at the outlet stream of the second MBBR reactor are sent to optimization software to obtain the optimal conditions of the remaining BAS process under-study. 


\subsection{Multicriteria optimization}

368 The BAS process is optimized for each alternative minimizing total cost index, which

369 include operation cost and wastewater quality criteria. As one optimal solution is obtained

370 for each alternative, 15 and 17 optimal solutions are obtained for case-study A and B

371 respectively. In general, it is observed that the decrease of nutrient dosage has a big impact

372 on objective index. The TCI lowest score alternative occurs for the lowest nutrient

373 dosage: 100:0.34:0.06 and 100:0.34:0.07 for case-study A and B respectively (TCI=0.208

$\left.374 € / \mathrm{m}^{3}, \mathrm{TCI}=0.244 € / \mathrm{m}^{3}\right)$.

375 Table 2 shows the optimal values of selected variables for the lowest score alternative

376 using TCI as objective function; the key characteristic of BAS process is the low sludge

377 yield (Tn TSS/ Tn CODf removed) without compromising treatment efficiency, and

378 therefore the sludge yield and efficiency appears as key variables. First of all, it is

379 observed that the comparison between the key variables in Table 1 (regular operational

380 conditions) and Table 2 (optimal values using TCI as objective function) shows that the

381 optimal conditions decrease the sludge yield to the half respect to the regular operational

382 conditions (from 0.207 to $0.108 \mathrm{Tn}$ TSS/Tn COD removed) and a little decrease of the

383 efficiency is also observed (from 35.4 to 34.5 Tn COD removed /day) for case-study A.

384 For case study B, similar decreases are observed for the best alternative: sludge yield from

3850.155 to 0.082 and efficiency decrease from 28.3 to 27.9Tn COD removed /day. 
Table 2. Optimal values of the operation conditions for the best alternative minimizing 391 total cost index (TCI) before and after the decision making process.

\begin{tabular}{|c|c|c|c|c|}
\hline \multirow{2}{*}{$\begin{array}{l}\text { Variables and Index } \\
\text { Optimal solutions }\end{array}$} & \multicolumn{2}{|c|}{$\begin{array}{c}\text { Optimal values before decision } \\
\text { making process }\end{array}$} & \multicolumn{2}{|c|}{$\begin{array}{c}\text { Optimal values } \underline{\text { after }} \text { decision } \\
\text { making process }\end{array}$} \\
\hline & $\begin{array}{c}\text { Case study } \\
\text { A }\end{array}$ & $\begin{array}{c}\text { Case study } \\
\text { B }\end{array}$ & $\begin{array}{c}\text { Case study } \\
\text { A }\end{array}$ & $\begin{array}{c}\text { Case study } \\
\text { B }\end{array}$ \\
\hline \multicolumn{5}{|l|}{ Manipulated Variables } \\
\hline $\mathrm{COD}_{\mathrm{f}}: \mathrm{N}: \mathrm{P}$ & $100: 0.34: 0.06$ & $100: 0.34: 0.07$ & 100:0.54:0.07 & 100:0.45:0.10 \\
\hline $\mathrm{Q}_{w}\left(\mathrm{~m}^{3} / \mathrm{day}\right)$ & 461 & 313 & 1.218 & 655 \\
\hline $\mathrm{R}(\%)$ & 109 & 82 & 109 & 82 \\
\hline \multicolumn{5}{|l|}{ Objective Indexes } \\
\hline TCI $\left(€ / \mathrm{m}^{3}\right)$ & 0.208 & 0.244 & 0.223 & 0.270 \\
\hline EQI (Kg pollution/m³) & 0.684 & 0.541 & 0.680 & 0.593 \\
\hline OCI $\left(€ / \mathrm{m}^{3}\right)$ & 0.114 & 0.170 & 0.130 & 0.189 \\
\hline \multicolumn{5}{|l|}{ Key variables } \\
\hline $\begin{array}{l}\text { Sludge yield (Tn TSS/Tn } \\
\text { COD removed) }\end{array}$ & 0.108 & 0.082 & 0.155 & 0.108 \\
\hline $\begin{array}{l}\text { Efficiency (Tn COD } \\
\text { removed/day) }\end{array}$ & 34.5 & 27.9 & 35.4 & 28.3 \\
\hline \multicolumn{5}{|c|}{ Technical decision making variables } \\
\hline SRT (days) & 39 & 51 & 17 & 28 \\
\hline $\mathrm{NO}\left(\mathrm{g} / \mathrm{m}^{3}\right)$ & 5.4 & 1.8 & 7 & 3.8 \\
\hline $\mathrm{TN}\left(\mathrm{g} / \mathrm{m}^{3}\right)$ & 5.9 & 1.9 & 6.5 & 4 \\
\hline$P\left(g / m^{3}\right)$ & 0.1 & 0.2 & 0.3 & 0.6 \\
\hline
\end{tabular}

392 Value: Values that not fulfil the refine operation bounds.

393 Figure 4 shows in a box plot fashion the summary of effluent quality and operating cost

394 indexes for all studied alternatives when total cost index is minimized. The lowest values

395 of EQI and OCI correspond with the lowest nutrient dosage. Figure 4 also compares the

396 optimal results with the results of the regular operational conditions. It is observed that

397 for nearly all of the alternatives the operating cost and the effluent quality index values

398 are lower than the regular operational conditions in both case studies. 


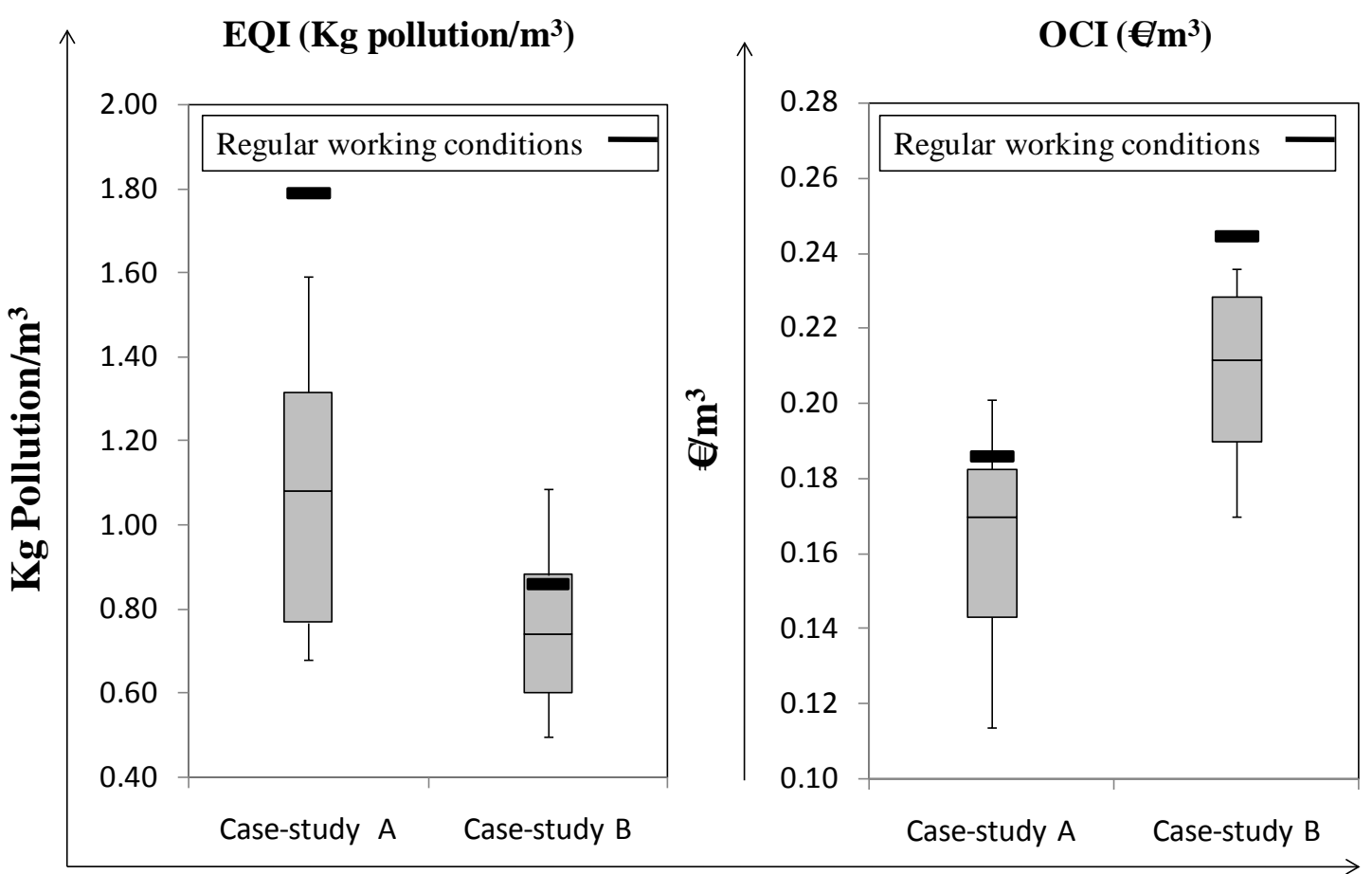

Case-studies

400 Figure 4. Box plots for the distribution of EQI and OCI indexes in case-study A (17 401 alternatives) and case-study B (15 alternatives) when TCI is minimized, and the comparison with the results at the regular working conditions.

403

404 Figure 5 show the contribution of each particular criterion on the effluent quality (EQI) 405 and operating cost (OCI) indexes for the lowest and the highest values of nutrient dosage 406 when TCI in minimized. In general, the lower the nutrient dosage in the influent, the 407 lower Qw is purged and higher SRT is obtained and consequently: i) less nitrogen and phosphorous are discharged in the effluent and less nitrogen is available in the AS reactor resulting in a decrease of nitrification rate and, therefore, less nitrogen is oxidized to 410 nitrate (NO) by autotrophic microorganisms and, ii) more TSS is discharged in effluent resulting in increase of COD and BOD. For these reasons, when the nutrient dosage is the 412 lowest, COD contributes up to $63 \%$ and $66 \%$ of the pollution discharge in case-study A 413 and B respectively and NO contributes 7-16\%. When the nutrient dosage is the highest, 
414 the COD contributes $25-30 \%$, NO contributes $30-35 \%$ and P contributes $31-33 \%$. In

415 relation to OCI there is a lower influence of the nutrient concentration; in both case-study,

416 it is remarkable that when the nutrient dosage is the lowest, CD is reduced $2-14 \%$ due to

417 airflow supplied in AS reactor is lower than in MBBR reactor.

418

419

420

421

422

423

424

425

426

427

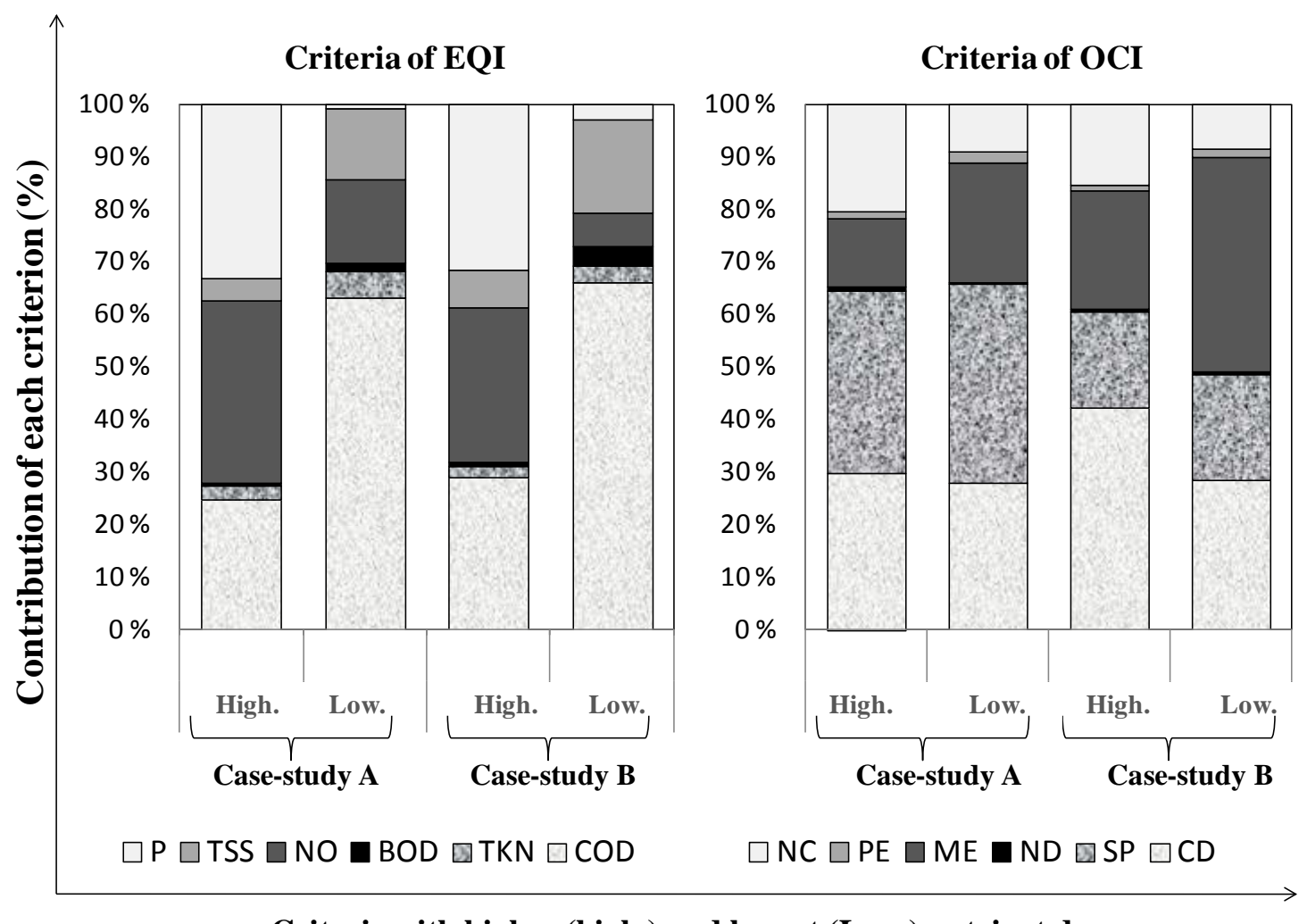

Criteria with higher (high.) and lowest (Low.) nutrient dosage

Figure 5. Contribution of each criterion on the effluent quality (EQI) and operating cost (OCI) indexes in each case-study for the highest (High.) and the lowest (Low.) values of nutrient dosage when TCI in minimized.

\subsection{Decision-making process.}

Decision making process is the last step of the methodology and includes the determination of some discrimination variables and their limits. The operational constrains and bounds included in the step 1 of the methodology are essential for the adequate running of an activated sludge process; however, there are other variables whose 
436 limits are recommendable but that nonetheless under diverse circumstances do not need

437 to be considered. At present there are more than 600 municipal or industrial Veolia

438 MBBR treatment plants in operation or under construction in more than 50 countries (van

439 Haandel and van der Lubbe 2015); some of these installations are used as pre-treatment

440 of activated sludge since MBBR is an upgrade to existing AS systems with little

441 disturbance but high efficiency. The diverse circumstances that can take places in each

442 installation support the idea of classifying the variables into essential and refinement.

443 The consideration of the refinement conditions in the decision making process of the 444 optimization methodology will help, a) to facilitate the trade-off among effluent quality 445 index, operating cost index and technical arrangement (Hakanen et al. 2013) and, b) to obtain BAS process adapted to different operation circumstances, for example: low pH wastewater, oversize installations, wastewater with different origin, low 448 Food/Microorganisms (F/M) ratio for AS process and excess of greases and oils among 449 others.

450 In the activated sludge process, the operational problems with biological origin are among 451 the most serious and most difficult matter to solve in wastewater treatment plants. Even 452 though the optimal conditions shown in Table 2 fulfil the appropriated operational conditions for BAS process of Figure 2, in the refinement conditions three biological aspects are pointed related with the growth of microorganism: i) "bulking” since too low nutrient dosage can bring excessive growth of filamentous bacteria (van Haandel and van 456 der Lubbe 2015; Welander et al. 2002) that leads to solid-liquid separation problems 457 (Flores-Alsina et al. 2009), ii) "pin-point floc" due to the formation of the old and overoxidised sludge produce by endogenous metabolism (Comas et al. 2003) and iii) rising sludge due to denitrification in the secondary settler where nitrates are converted 
to nitrogen gas (Flores-Alsina et al. 2010). The refinement operation bounds included in the decision making variables are divided into two categories:

\section{Bulking and decrease of COD removal efficiency}

Until now, the nutrient dosage has been considered in the influent; however, very low concentrations of the TN and $\mathrm{P}$ in the effluent can mean too severe decrease of nutrient dosage resulting in sludge settleability (bulking) or even in a loss of COD removal efficiency (van Haandel and van der Lubbe 2015). For this reason, in this work has taken into account lower limits in the effluent for the concentration of TN of $4 \mathrm{~g} / \mathrm{m}^{3}$ and $0.3 \mathrm{~g} / \mathrm{m}^{3}$ for P as proposed by Welander et al. 2002.

It is observed at Table 2 (Bold figures) that the optimal solutions before decision making process do not fulfil some of the P or/and TN values in the effluent and therefore the undesirable bulking can occur.

\section{Risk of solid-liquid separation problems due to "pin-point-floc" and rising sludge} In addition to the TN and $\mathrm{P}$ bounds described above, two new technical requirements are now adding (Figure 2): i) concentration of nitrate (NO) and, ii) SRT in the AS reactor of the BAS process. Nitrate concentration in the secondary settler higher than $8 \mathrm{~g} / \mathrm{m}^{3}$ (Henze et al. 1993) is not recommended since the bottom layer of the secondary settler (where nitrogen bubble formation through biological denitrification) can break into small flocs and part of the sludge would flow out into the effluent; furthermore, an increase of COD, BOD, TKN and $\mathrm{P}$ in the effluent would occurs (Flores-Alsina et al. 2010).

High values of SRT produce an old and overoxidised sludge with large amount of inert matter called "pin-point floc" (Comas et al. 2003). 40 days is selected in this work as upper limit of SRT because the hydraulic retention time (HRT) in AS reactor 
is greater than 30 hours and it is considered an extended aeration tank which optimal SRT value lower or equal to 40 days (Tchobanoglous et al. 2003).

486 Above described operational bounds of the effluent are included in step 4 of the 487 optimization methodology shown in Figure 2. Figure 6 shows the pareto graph between 488 the sludge yield and TCI index values for all alternatives before (red symbols) and after 489 the decision making process (green symbols) as well as the regular operational conditions 490 (black and brown symbols). It is observed that in both case-studies the minimum values 491 of TCI and sludge yield agree but only few alternatives (green symbols) fulfil the 492 refinement bounds.

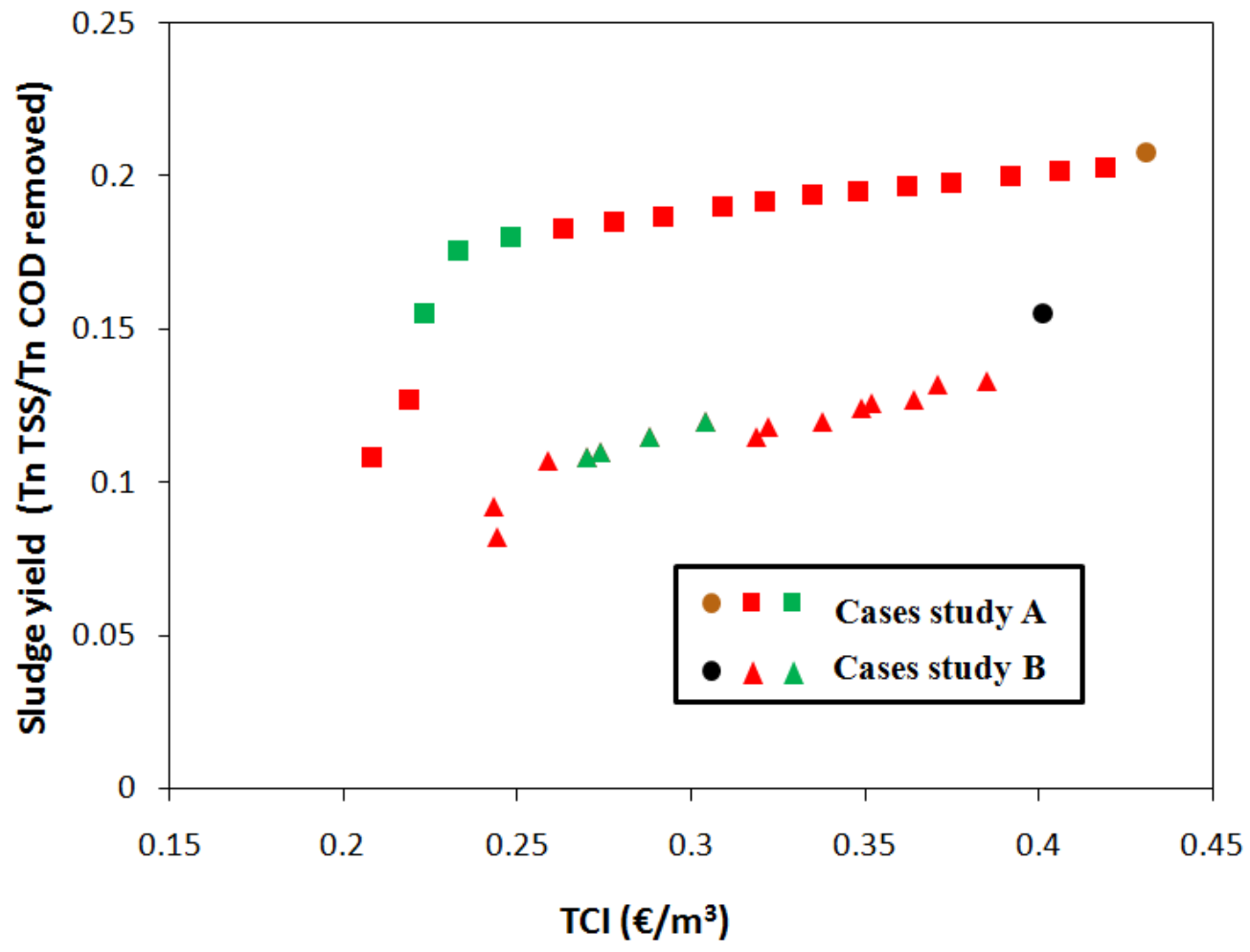

494 Figure 6. Pareto graph between sludge yield and TCI index values before decision making 495 process in Case Study A $(\square)$ and B $(\mathbf{\Delta})$ and after the decision making process in Case 496 Study A ( $(\mathbf{)})$ and B ( $(\Delta)$. The regular operational conditions are represented in Case Study 497 A (O) and Case Study B (O). 
504

505

506

507

508

509

510

511

512

513

514

515

516 Finally, the right column in Table 2 shows the optimal values of variables for the best

517 alternative for case-study A and B after decision making selection. It is observed that the

Figure 7 shows the 3 (case-study A) and 4 (case-study B) alternatives that fulfil the values of refinement operation bounds simultaneously and compares the results of these alternatives respect to the regular operational conditions. It is observed in Figure 7 reductions of TCI up to $45 \%$ and $25 \%$ for case-study A and B respectively in comparison with the regular operational conditions, mainly due to the high reductions of EQI (up to $60 \%$ in $\mathrm{A}$ and up to $31 \%$ in $\mathrm{B})$.
Case-study A

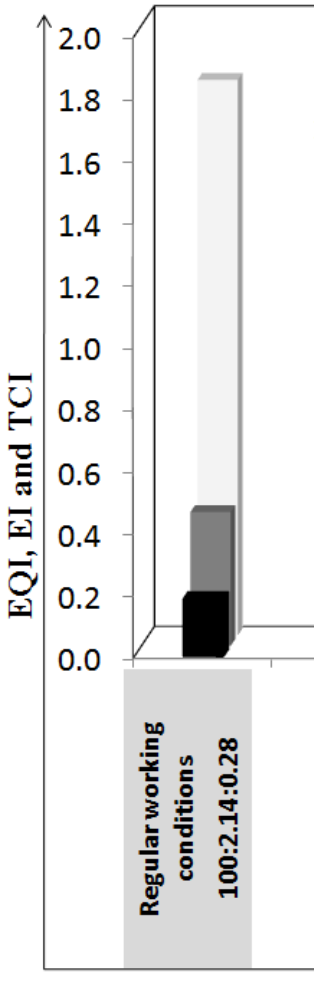
EQI $\left(K g\right.$ pollution $\left./ \mathbf{m}^{3}\right)$ $\operatorname{OCI}\left(€ / \mathbf{m}^{3}\right)$ $\operatorname{TCI}\left(€ / \mathbf{m}^{3}\right)$
Case-study B 1.2
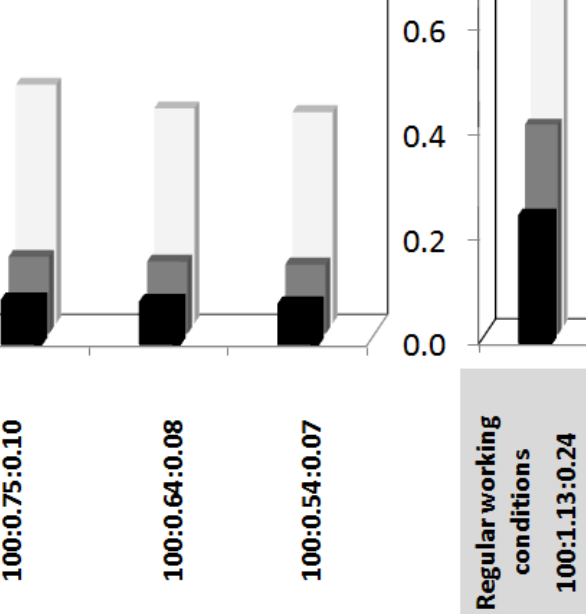

Regular working conditions and optimal solutions

Figure 7. Optimal values of the feasible alternatives for the effluent quality index (EQI), operating cost index (OCI) and total cost (TCI) index after of the decision making and the comparison with the regular operational conditions.
nutrient dosage and sludge yield are higher than before to decision making process. 
519 Besides, the sludge yields in Table 2 are inside the range of others studies as such as 520 Malmqvist et al. 2007 and Rankin et al. 2007.

521 The application of the proposed methodology allows a reduction of the operating cost of

522 treatment $\left(€ / \mathrm{m}^{3}\right)$ up to 30\% whereas the efficiency (Tn COD removed per day) do not 523 decrease respect to the regular operational conditions used in the full-scale wastewater 524 plant. Furthermore, the quality of the wastewater is also much better since the EQI (Kg 525 pollution $/ \mathrm{m}^{3}$ ) is reduced up to $62 \%$.

526 In Figure 8, the different contributions of each evaluation criterion for the best alternative 527 are shown. The major contribution to effluent quality index (EQI) is the COD (21 \% in 528 case-study A and $17 \%$ in case-study B), since the contribution of NO and P are reduced 529 in comparison to regular operational conditions due to low nutrient dosage. Respect to 530 the major contribution to operation cost index (OCI) after decision making is the energy 531 consumption for carbonaceous demand (CD) (21\% in case-study A and $28 \%$ in case532 study B) due to the BAS process in this work was designed to the high removal of COD 533 in aerobic conditions (Revilla et al. 2016a); moreover, a large decrease in the nutrient cost 534 (NC) is observed compared to regular operational conditions. 


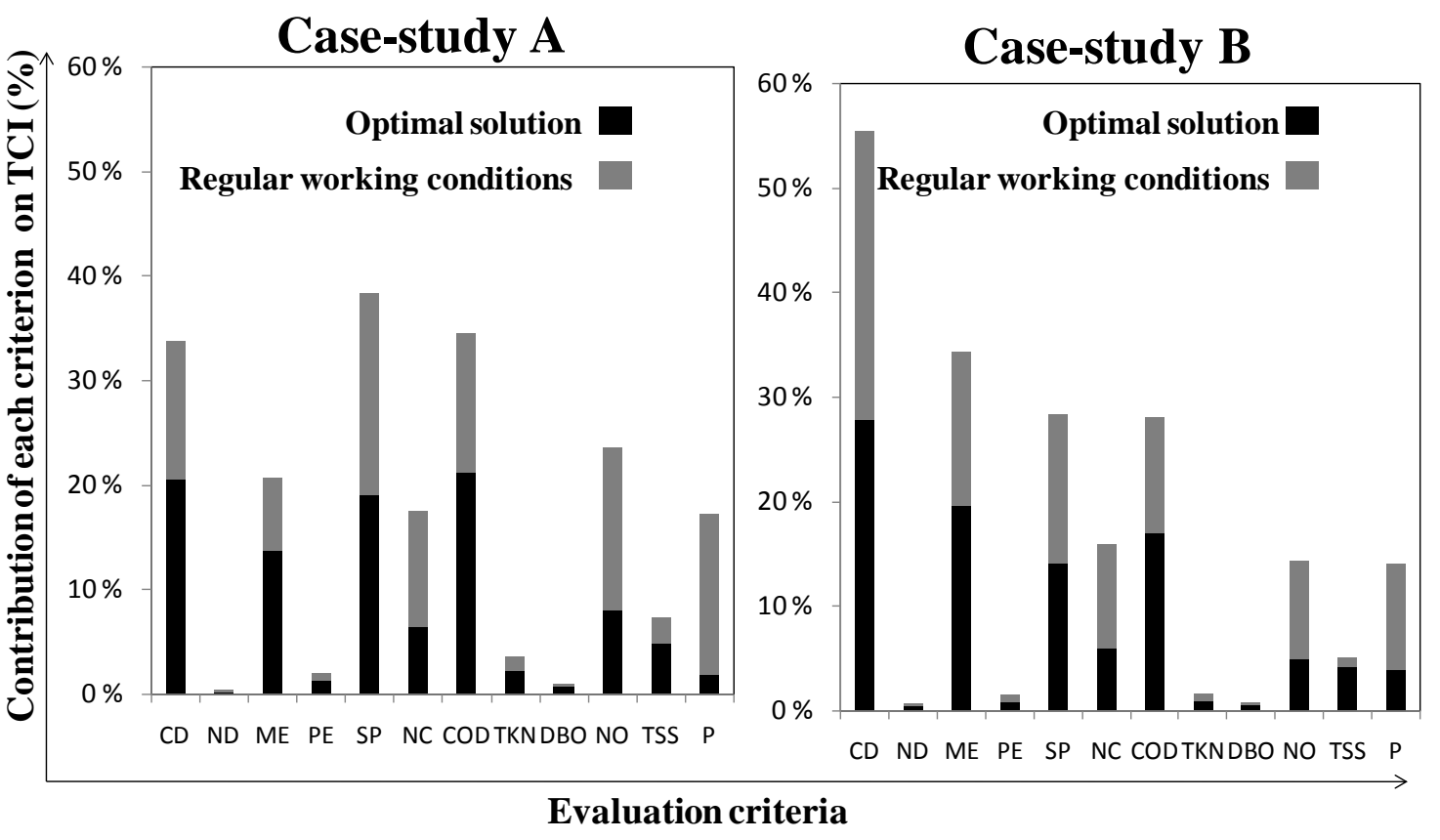

\section{Evaluation criteria}

536 Figure 8. Contribution of evaluation criteria on the total cost index (TCI) of the optimal 537 solution compared to the regular operational conditions.

\section{Conclusions}

This paper presents a methodology that allows obtaining the optimal operational conditions for an industrial BAS plant treating highly COD wastewater under limited nutrient conditions. The methodology formulates BAS process as a mathematical optimization problem combining economic and environmental criteria as objective function and overtakes some challenges such as high number of (non-linear) equations and variables and the dynamic and spatial distribution behaviour of components into the biofilm. The optimization methodology is divided into four consecutive steps: i) generation of alternatives, ii) simulation of the MBBR reactors (biofilm) until steadystate, iii) multicriteria optimization and iv) decision making process. The optimization methodology establishes priority levels of several technical specifications (essential and refinement variables) related with the activated sludge tank and secondary clarifiers. 
550 The application of this methodology at two industrial-scale case studies from viscose and

551 cellulose wastewaters allows a reduction of quantity of pollutants per $\mathrm{m}^{3}$ wastewater

552 treated up to $60 \%$ and a reduction of the operating costs $\left(€ / \mathrm{m}^{3}\right)$ up to $30 \%$ in comparison

553 with the regular operational conditions used in the industrial BAS wastewater plant.

\section{Acknowledgements}

555 The authors would like to thank SNIACE Company for their help and support during the 556 wastewater sampling and characterization at industrial plant.

\section{References}

Amanatidou, E., Samiotis, G., Trikoilidou, E., Pekridis, G., \& Taousanidis, N. (2015a). Evaluating sedimentation problems in activated sludge treatment plants operating at complete sludge retention time. Water Research, 69, 20-29. doi:10.1016/j.watres.2014.10.061

Amanatidou E., Samiotis G., Bellos D., \& Pekridis G. (2015b). Net biomass production under complete solids retention in high organic load activated sludge process. Bioresource Technology,182, 492-502.

Bakos, V., Kiss, B.,\& Jobbágy, A. (2016). Problems and causes of marginal nutrient availability in winery wastewater treatment. Acta Alimentaria, 45(4), 532-541.

Chen, W., Lu, X., \& Yao, C. (2015). Optimal strategies evaluated by multi-objective optimization method for improving the performance of a novel cycle operating activated sludge process. Chemical Engineering Journal, 260, 492-502. doi:10.1016/j.cej.2014.08.087 
572 Comas, J., Rodríguez-Roda, I., Gernaey, K. V., Rosen, C., Jeppsson, U., \& Poch, M. 573 (2008). Risk assessment modelling of microbiology-related solids separation 574 problems in activated sludge systems. Environmental Modelling and Software, 23(10-11), 1250-1261. doi:10.1016/j.envsoft.2008.02.013

576

577

578

Comas, J., Rodríguez-Roda, I., Sànchez-Marrè, M., Cortés, U., Freixó, A., Arráez, J., \& Poch, M. (2003). A knowledge-based approach to the deflocculation problem: Integrating on-line, off-line, and heuristic information. Water Research, 37(10), 2377-2387. doi:10.1016/S0043-1354(03)00018-6

Comeau, Y., Peteesen, B., Stuart, P., Perkier, M., Graff, S., \& Asselin, C. (2003). Activated sludge yield reduction by the low sludge production (LSP) process results are promising. Pulp and Paper Canada, 104(8), 40-42.

Copp, J.B., (2002). The COST simulation benchmark. Description and simulator manual, Office for Official Publications of the European Communities, Luxembourg.

Dai, H., Chen, W., \& Lu, X. (2016). The application of multi-objective optimization method for activated sludge process: A review. Water Science and Technology, 73(2), 223-235. doi:10.2166/wst.2015.489

Descoins, N., Deleris, S., Lestienne, R., Trouvé, E., \& Maréchal, F. (2012). Energy efficiency in waste water treatments plants: Optimization of activated sludge process coupled with anaerobic digestion. Energy, 41(1), 153-164. doi:10.1016/j.energy.2011.03.078

El Shorbagy, W., Nabil, N., \& Droste, R. L. (2013). Optimization of A20 BNR Processes Using ASM and EAWAG Models: Model Performance, Water Environment Research. 85 (12) 2271-2284 doi:10.2175/106143013X13596524517102 
595 Espírito Santo, I. A. C. P., Costa, L., \& Fernandes, E. M. G. P. (2013). On optimizing a 596 WWTP design using multi-objective approaches. Engineering Letters, 21(4), 193597202.

598 Fan, C., Kao, C. F., \& Liu, Y. H. (2017). Quantitative characterization of organic 599

600 601

602

603

604

605

606

607

608

609

610

611

612

Flores-Alsina, X., Comas, J., Rodriguez-Roda, I., Gernaey, K. V., \& Rosen, C. (2009). Including the effects of filamentous bulking sludge during the simulation of wastewater treatment plants using a risk assessment model. Water Research, 43(18), 4527-4538. doi:10.1016/j.watres.2009.07.033

Flores-Alsina, X., Gallego, A., Feijoo, G., \& Rodriguez-Roda, I. (2010). Multipleobjective evaluation of wastewater treatment plant control alternatives. Journal of Environmental

Management,

91(5), 1193-1201. doi:10.1016/j.jenvman.2010.01.009

Flores-Alsina, X., Rodríguez-Roda, I., Sin, G., \& Gernaey, K. V. (2008). Multi-criteria evaluation of wastewater treatment plant control strategies under uncertainty. Water Research, 42(17), 4485-4497. doi:10.1016/j.watres.2008.05.029

Foscoliano, C., Del Vigo, S., Mulas, M., Tronci, S., (2016). Predictive control of an activated sludge process for long term operation. Chemical Engineering Journal, 304, 1031-1044.

Freedman, D. L., Payauys, A. M., \& Karanfil, T. (2005). The effect of nutrient deficiency on removal of organic solvents from textile manufacturing wastewater during 

activated sludge treatment. Environmental Technology, 26(2), 179-188. doi:10.1080/09593332608618570

Garrido-Baserba, M., Reif, R., Molinos-Senante, M., Larrea, L., Castillo, A., Verdaguer, M., \& Poch, M. (2016). Application of a multi-criteria decision model to select of design choices for WWTPs. Clean Technologies and Environmental Policy, 18(4), 1097-1109. doi:10.1007/s10098-016-1099-x

Gray, N.F. (2004). Biology of wastewater treatment. $2^{\text {nd }}$ edition. World Scientific. Dublin.

Guerrero, J., Guisasola, A., Vilanova, R., \& Baeza, J. A. (2011). Improving the performance of a WWTP control system by model-based setpoint optimisation. Environmental Modelling and Software, 26(4), 492-497. doi:10.1016/j.envsoft.2010.10.012

Hakanen, J., Miettinen, K.,\& Sahlstedt, K. (2011). Wastewater treatment: New perspectives provided by interactive multiobjective. Decission Supoort System, 51(328), 337.

Hakanen, J., Sahlstedt, K., \& Miettinen, K. (2013). Wastewater treatment plant design and operation under multiple conflicting objective functions. Environmental Modelling \& Software, 46, 240-249. doi:10.1016/j.envsoft.2013.03.016

Henze, M. (2008). Modeling of Aerobic Wastewater Treatment Processes. In Biotechnology (Vol. 11-12, pp. 417-427). Wiley. doi:10.1002/9783527620999.ch201

Henze, M., Dupont, R., Grau, P., \& de la Sota, A. (1993). Rising sludge in secondary settlers due to denitrification. Water Research, 27(2), 231-236. doi:10.1016/00431354(93)90080-2 
Hreiz, R., Latifi, M. A., \& Roche, N. (2015a). Optimal design and operation of activated sludge processes: State-of-the-art. Chemical Engineering Journal, 281, 900-920. doi:10.1016/j.cej.2015.06.125

Hreiz, R., Roche, N., Benyahia, B., \& Latifi, M. A. (2015b). Chemical Engineering Research and Design Multi-objective optimal control of small-size wastewater treatment plants. Chemical Engineering Research and Design, 102, 345-353. doi:10.1016/j.cherd.2015.06.039

Hussain, A., Kumar, P., \&Mehrotra, I. (2015). Nitrogen and phosphorus requirement in anaerobic process: A review. Environmental Engineering and Management Journal, 14(4), 769-780.

Kamali, M., \& Khodaparast, Z. (2015). Review on recent developments on pulp and paper mill wastewater treatment. Ecotoxicology and Environmental Safety, 114, 326-342. doi:10.1016/j.ecoenv.2014.05.005

Kim, M., Kim, M-J., Pyo, S-H., Lee, S-C., Ghorbannezhad, P., Foo, D.C.Y., Yoo, C-K., (2015). Greenhouse emission pinch analysis (GEPA) for evaluation of emission reduction strategies, Clean Technology and Environmental Policy 18(5), 1381-1389.

Li, B., Qiu, Y., Zhang, C., Chen, L., \& Shi, H. (2016). Understanding biofilm diffusion profiles and microbial activities to optimize integrated fixed-film activated sludge process. Chemical Engineering Journal, 302, 269-277. doi:10.1016/j.cej.2016.05.048

Malmqvist, Å., Welander, T., \&Olsson, L. E. (2007). Long term experience with the nutrient limited BAS process for treatment of forest industry wastewaters. Water Science and Technology, 55(6), 89-97. 
664

665

666

667

668

669

670

671

672

673

674

675

676

677

678

679

680

681

682

683

684

685

686

Rankin, A., Aert, M. V. A. N., \& Welander, T. (2007). Low sludge yield biofilm activated sludge ( BAS ) upgrade - Quesnel River Pulp. Tappi Journal, 6(5), 17-22.

Revilla, M., Galán, B., \& Viguri, J. R. (2016a). Analysis and modelling of predation on biofilm activated sludge process: Influence on microbial distribution, sludge production and nutrient dosage. Bioresource Technology, 220, 572-583. doi:10.1016/j.biortech.2016.08.107

Revilla, M., Galán, B., \& Viguri, J. R. (2016b). An integrated mathematical model for chemical oxygen demand (COD) removal in moving bed biofilm reactors (MBBR) including predation and hydrolysis. Water Research, 98, 84-97. doi:10.1016/j.watres.2016.04.003

Rivas, A., Irizar, I., \& Ayesa, E. (2008). Model-based optimisation of Wastewater Treatment Plants design. Environmental Modelling and Software, 23(4), 435-450. doi:10.1016/j.envsoft.2007.06.009

Sointio, J., Rankin, A., \&van Aert, M. (2006). Biofilm Activated Sludge process at Quesnel River Pulp installation. Environmental Science \& Engineering Magazine. 22-24.

Sweetapple, C., Fu, G., \& Butler, D. (2014). Multi-Objective Optimisation of Wastewater Treatment Plant Control to Reduce Greenhouse Gas Emissions. Water Research,55(0), 52-62. doi:10.1016/j.watres.2014.02.018

Tchobanoglous, G., Burton, F.L., \&Stensel, H.D. (2003). Wastewater Engineering: Treatment and Reuse. McGrawHill Education.

van Haandel, A.,\& van der Lubbe, J. (2015). Handbook of biological wastewater treatment. (I. Publications, Ed.). 
687 Vanrolleghem, P.A., \&Gillot, S. (2002). Robustness and economic measures as control benchmark performance criteria. Water Science and Technology, 45(4-5), 117-126.

von Sperling, M. (2007). Activated sludge and aerobic biofilm reactors. IWA publishing.

690 doi:10.2166/9781780402123.

691 Welander T. Olsson LE, \& Fasth C. (2002). Nutrient-limited biofilm pretreatment: an 692 efficient way to upgrade activated sludge plants. Tappi Journal, 1(4), 20-26.

693 Zhou, Z., Shen, X., Jiang, L. M., Wu, Z., Wang, Z., Ren, W., \& Hu, D. (2015). Modeling 694 of multimode anaerobic/anoxic/aerobic wastewater treatment process at low 695 temperature for process optimization. Chemical Engineering Journal, 281, 644-650. 696 doi:10.1016/j.cej.2015.07.017

697 